\title{
The Interpretative Meaning of Stigma Experience in Adolescent Living with CLP
}

\author{
Ruoh-Lih Lei \\ Associate Professor, Associate Director \\ HungKuang University Department of Nursing \\ Taichung ,Taiwan \\ lilylei@hk.edu.tw \\ Ptlene Minick \\ Associate Professor, Doctoral Program Coordinator \\ School of Nursing \& Health Professions \\ Georgia State University.Georgia, USA \\ pminick@gsu.edu
}

\author{
Chi-Chun Chin \\ Associate Professor \\ Kaohsiung Medical University Department of Nursing \\ Kaohsiung ,Taiwan \\ chichun@kmu.edu.tw \\ Hui-Ching Liu \\ Director, Hung-Chi Psychiatric Hospital \\ Taipei ,Taiwan \\ annalhc@ms15.hinet.net
}

\author{
Shih-Ching Fang \\ Research Assistant ,HungKuang University \\ Department of Nursing,Taichung County,Taiwan \\ h.chung513@gmail.com
}

\begin{abstract}
CLP is one of the common congenital defects. Significant advances have been made in our understanding of Cleft Lip and Plate (CLP) in specific physical and psychosocial problems. However, studies of subjective stigma experience in adolescents with CLP is limited.

From humanistic nursing perspective, a qualitative research design, hermeneutics phenomenology, was adopted, using depth interviews with participants who were selected by purposive sampling method. A total of 9 informants participated in this study, after clarifying pre-understand, the interviews were transcribed and a hermeneutical circle analysis of their thematic contents were carried out.

The result showed that the interpretative stigma experience was described as "crossing the fog of being noticed: living with determination". Three aspects were included: 1 . the fact of being internalized: living with blood relatives - acceptance and rejection of the original family; 2 . the contradiction of being noticed: living with the rift - dissimilation and assimilation of others; 3 . the possibility of planning for the future: living with CLP - determination for existing dilemma.

The findings of this study may provide healthcare staff a useful reference when caring for disabled people with visible facial scars. It may also provide guidance in developing a nursing care plan with intersubjectivity and fore-structure of understanding to meet the needs of these patients and enhance the quality of their care.
\end{abstract}

Keywords-stigma experience; CLP; adolescents

\section{INTRODUCTION}

Cleft lip and CLP (both hereafter to be referred to as CLP) are two of the most common congenital craniofacial anomalies in Taiwan.(Lei et al,. 2013.) Treatment of children with CLP usually involves surgery, a multidisciplinary health care team(s), and care by parents over a long period of time (Kelton, 2001; Lei et al,. 2010.). Eeven after completion of a program of therapy, however, an individual with CLP may have appearance and speech problems (Richman, Holmes, \& Eliason, 1985; Strauss, 2001; Snyder, Bilboul, \& Pope, 2005). In addition, the psychosocial identity of individuals with CLP becomes a significant issue in a worldwide cultural climate in which physical attractiveness is desired and "what is beautiful is good" (Calvert, 1988; Dion \& Berscheid, 1972; Hagman, 2002). Moreover, even with CLP, adolescence is associated with a number of challenges, problems, and crises that may be difficult to overcome (Persson, Aniansson, Becker, \& Svensson, 2002). Therefore, the general assumption is that adolescents with CLP have appearance and articulation defects which can disturb their psychosocial adjustment (Hunt, Burden, Hepper, \& Johnston, 2005; Pope \& Snyder, 2005).

However, the assumption that people with CLP experience an abnormally high level of psychosocial problems has not been clearly established (Endriga \& Kapp-Simon, 1999; Hunt, Burden, Hepper, \& Johnston, 2005). For instance, even though concerns over facial appearance are likely to coincide with concerns regarding speech (Ramstad et al., 1995), some of the CLP research has indicated that adolescents with CLP generally have positive self-concepts (Richman, 1983) and that few adolescents and young adults with CLP are dissatisfied with their speech (Noar, 1991).

Whether the research has pointed to negative or positive aspects of adolescents with CLP, most studies have reflected researchers' received view of science to explain or prove the impact of CLP on adolescents (Link et al., 1997; Marcusson, 2001; Hunt, Burden, Hepper, \& Johnston, 2005). As Meleis 
reminded us the guiding paradigm for nursing profession has been more open, more subject to experiences and personal interpretation, therefore, a perceived view (1997). In the meantime, in this work, we would like to understand what the phenomenon of the tacit life of participant is first and, after that, can know what they need to care next step. Until now, no work has focused on the interpretative meaning in adolescent living with CLP. The purpose of this study was to explore the interpretative stigma experience in adolescent living with CLP.

\section{METHODOLOGY OF THE STUDY}

\section{A. The Process of Studying}

This study used nursing perspectives and adopted hermeneutic phenomenology to explore the meaning of stigma experience in adolescents with CLP. The researchers used the purposive sampling method to recruit 9 adolescents with CLP as participants. Prior to conducting in-depth interviews to collect information about the stigma experience of the subjects, the researchers first clarified their own fore-structure of understanding. Once the interview data was transcribed into 30 texts, the process of hermeneutical circle was utilized to complete an inquiry into the interpretative stigma experience in adolescent living with CLP.

\section{B. The Hermeneutical Circle of Text}

The researchers used the hermeneutic circle method. A 3stage presentation was adopted. In stage one, the interview texts of the participants and their life stories were restructured in chronological order. Eleven stories of adolescents with CLP assisted the researchers to delve deeply into their living world. In stage two, thematic analysis obtained themes of stigma experience based on the stigma experiences described by the participants and formed a framework. In stage three, the relationship of inter-subjectivity of the participants was used as the baseline. Using the method of situated-ness, the eleven participants interviewed recalled and associated live life stories that formed an integrated discourse of stigma experiences in adolescents with CLP. It also indicated the interpretative stigma experience in adolescent living with CLP.

\section{Ethical Consideration}

Ethics approval for this study was given by the Kaohsiung Medical University Chung-Ho Memorial Hospital. Parents and child (participant) were approached individually and needed to fill out the consent form together.

\section{TRUSTWORTHINESS}

The trustworthiness of the data was enhanced by the transparent process of analysis, the involvement of three independent researchers. The researchers read and compared ideas based on the transcripts and searched for confirming evidence during the analysis (Hodgkinson, \& Lester, 2002; Holloway \& Wheeler, 2002).

\section{INTERPRETATIVE MEANING OF LIVING WITH CLP}

The result show that the interpretative meaning of stigma experience was described as "crossing the fog of being noticed: living with determination". Three aspects were included: 1 . the fact of being internalized: living with blood relatives acceptance and rejection of the original family; 2 . the contradiction of being noticed: living with the rift dissimilation and assimilation of others; 3 . the possibility of planning for the future: living with CLP - determination for existing dilemma.

Furthermore the interpretative stigma experience in adolescent living with CLP was "crossing the fog of being noticed: living with determination". Adolescents with CLP reconstructed the scenes of being a newborn from the description of their parents or relatives who witnessed their birth. It brought back previous scenes in their life. It eliminated the distance and allowed them to "notice" their CLP.

CLP is a manifest and visible congenital "difference". The content of interviews showed that newborns with congenital differences of CLP create concern at birth. Concern begins from the "first sight" of medical staff and their first doubt "eh...?"; and is immediately followed by parents shaking their heads after "seeing the child". The participants were not aware of the attention they faced when they were newborns. While they were describing their stories of birth, they were beginning to understand what actually happened and how the medical staff and their parents reacted. The first key notice of their CLP for them and their parents was seeing the shock and fright described when they first saw the newborn. From the stories of the participants, the shocked gaze of parents was reflected in the recalled memory. The newborn is seen in the memory. How much sorrow, depression and remorse are hidden in their mothers' view of her newborn? What kind of feelings are the parents hiding behind the fog of being noticed? Some parents choose to see the situation bravely; some parents would rather avoid facing the truth. Differences in the reaction of every parent represent the different feelings hidden behind them. The feeling is denoted when the parents are observing the participants. It gives the first possible answer to "who am I" when the participants are exploring their stigma experience.

Some parents did not share stories about childhood. The participants regretted the lack of stories since they were seeking their roots; a blank space in their lives that hides some facts that they were not willing to face. Some parents mentioned, "The pictures of your birth are kept in your aunt's home", or joked, "that was terrible and of course I did not shoot!". Hiding the past increased the confusion of the participants in shaping their lives. Their inherited CLP would make their family "not willing to see them". Regardless of the receipt of special care, they are placed under a special "care". Between the acceptance and rejection of the original family, they are cared with confusion and join another person.

The original family cares about the adolescent with CLP. The care extends to school areas. Although some of the mothers requested the teachers' help in advance, stigmatization by classmates, attacking or bullying of their children was unavoidable. The process began with being noticed. As one of the participants, Guan-Yu, described, "the differences were in the eye contacts; the expression in one's eyes, isolation, an atmosphere, that kind of feelings..." The situations described by the participants began from the moment of "being noticed". The story started on the first school day. Because of the obvious defects in their physical 
looks, many people would look at them. When being noticed, the adolescent felt that some people's looks felt good while some hid malice. Although the notice from others located the adolescents with CLP in time and space, the attention was mutual regardless of the discussion. They noticed one another simultaneously.

Being a target of attention, the stigma experience of the participants gradually materialized. There are distance and position in space and time; however, the experience of the participants showed that they disliked being noticed. This process removed the distance and forced the participants to develop close contact with others. The ego of the participants was destroyed in each bullying. The presence of others did not refer to the fact that they are appearing in the world of the participants; rather, that they are an invasive violation of the participants. Such attention solidified the distance of the participants. The judgmental public perspective intervened without limitation. The presence of CLP in the adolescent perhaps caused confusion in others. With the beginning of intersubjectivity, their peers did not know how to treat them. What is CLP? Is it normal or abnormal?

Min-Min’s aunt unintentionally blamed her mother with "you owe your child fairness". It destroyed the "seen" created painstakingly by Min-Min and her mother over the years. It explained that a deep sense of guilt is hidden behind her mother's eyes. Such notice reflected the disappointment of her mother that my child "is never good enough". They had gradually and peacefully proceeded through this perilous process in her growth. Within the vague notice, the doubt of "who am I" is hidden. These concerns are very likely to result in confusion in adolescents with CLP.

The language of the subjects is another focus of notice. Language is an expression of ideas and self-expression. For the participants with CLP who cannot verbally communicate without difficulty, the pathway of communicating with others is broken. Language dilemma created a focus of notice. It resulted in "homelessness" and created identity dilemmas.

Ordinary people will look around the surroundings in living with others. When they encounter something special, they will stop and examine the situation. Noticing each other is seeing each other and is an affirmation of existence. It does not bring embarrassment and frustration. We live our lives being noticed; however, being noticed is a problem for the participants. In every second and minute of their lives when they are noticed, they feel the pain, the grief, the shame and understanding because of their CLP. They recall everything bad in the past. They are immersed in the fog-like dilemma again. Perhaps adolescents with CLP have to face this existing issue. Each notice is an inquiry of lives to them: "who are you"? "Are you identical to or different from everyone "? They cannot be as stable as others. They cannot be immersed in the public. The homeless feeling created by dilemmas has created their anxiety. They have to make constant decisions when facing dilemmas. Should I encounter the dilemma bravely? Should I seek my true self bravely or run away? This is a lifelong lesson for adolescents with CLP: crossing the fog of being noticed.
After clarification by hermeneutical circle, there are four levels of notice in our discussion. The first is the notice of others seeing the participants. Second, it is the notice of others perceived by the participants. As stated in the previous discussion, the notice of others does not necessarily equal the meaning perceived by the participants. The third level of notice is the participants seeing themselves. The final level defines the notice of all cultural frameworks on the participants. The four levels of notice are constantly repeated, associated and recalled. This seems to be the lesson for life for the participants. They must cross the fog of being noticed. They are destined to find the road to go through the fog. They want to see it clearly, what is this cleft? What are the others seeing?

For an ordinary person without a different appearance there are rarely special comparisons. They live at peace with everyone. The participants show concern about their body because of the observation from others. Identical or different cannot be distinguished simply by dichotomy. When they are seeking, they understand more clearly that "which part of me is identical to others, which part is different?" While reflecting on what different experience brought to the participants, we should understand that the participants are not only seeking the feeling of identical or different. Seeking also includes the process of self-identification of understanding and agreeing on "who am I" by realizing the individual, unique body experience.

In the process of identifying themselves as identical or different, perhaps one day the participants will see that they are different from some people but not all; or perhaps they cannot find the answer in their life-long inquiry. As Min-Min stated in the interview: "How to face different conflicts between our own identity crisis and public opinions will be our life-long lesson ".

\section{DISCUSSION}

The findings demonstrated that the adolescents living with CLP not only were facing up to and struggling against the stigma but, moreover, had been shaped by it. The adolescents sensed their being regarded as "abnormal beings" through others' awkward gaze. The participants repeatedly and in a variety of ways expressed their personal experiences of living with CLP in the context of what they perceived to be others' thoughts, feelings, and actions about their (the participants') particular condition of CLP. This reaffirms Merleau-Ponty's phenomenological view that we do not experience our physical body as an object among other objects in space, and that people sense their own body through the other (MerleauPonty, 1962; Moran, 2000).

Moreover, the process by which the adolescents with CLP were shaped by others is in accord with established conceptualizations of stigma. They consider themselves to be regarded as abnormal, because others have pointed out their permanent scars and unclear verbal articulation, which leads to Goffman's first type of stigma, (self-)abomination of the body, expressed by the adolescents in statements such as "I don't like myself," I think I'm ugly.” Moreover, according to the six factors of stigma, work of stigma Jones et al., (1984), condition of adolescent with CLP is belonged to obvious 
condition. They even go through continuity of operations, the secret of CLP still can't completely cover, the impact of CLP will induce the inerasable scar on face and further destroy aesthetic qualities long term, the ultimate outcome of young person with CLP would arise obscure articulation and hamper interaction and communication with others.

As for visible and invisible stigma, Goffman (1963) distinguished between two ways that stigma can be experienced. An individual may be discredited or discreditable. A discredited individual is one who shows visible signs of being different (Goffman 1963; Joachim \& Acorn, 2000). When signs are visible, those individuals are stigmatized and discredited by others. CLP belongs to this type of stigma. Discredited people manage the stress in relationships by disregarding painful occurrences (Dudley, 1983) or isolating themselves into subgroups in order to normalize their attributes (Becker 1981). In this study, the participants were "frustrated by social interaction" and seemed to hesitate to develop social relationships. For coping with a stigmatizing condition, parents or the adolescents would use covering, which is an attempt to minimize the effect of stigmatizing condition (Goffman, 1963; Mcmanus, Stubbing, \& Martin, 2006; Joachim \& Acorn, 2000). Covering minimizes visible effects and thereby decreases stress. Joking about a defect is an example of covering. It is an attempt to make "normals" feel comfortable. Covering can be an expression of wanting to fit in with 'normals' as well as with the group being stigmatized, for example, the participants stigma-betokened due to parent's intentional ignorance, which can make it hard to talk about the problem with their parents. The stigmatized individual may also use his stigma for "secondary gain," as an excuse for ill success that has come his way for other reasons (Goffman, 1963). Nevertheless, for adolescence with CLP, we found that parents or family members' initiative administered something nicer to cases, or even treat them better and it is different from the description of literature.

\section{IMPLICATIONS AND CONCLUSIONS}

The findings suggest that adolescents with CLP feel stigma but do not enact stigma within the process of being stigmatized, suffering from it in various ways, and trying to face up to it . Moreover, CLP appears to be linked to stress, which means that coping and de-stigmatization strategies for CLP adolescents, their families, and larger society need to be further developed, for example, by creating adaptation models to improve the quality of life for adolescents with CLP in the future.

\section{ACKNOWLEDGEMENTS}

We deeply appreciate the participation of the 9 individuals and their families.

\section{REFERENCES}

[1] Calvert, J. D. (1988). Physical attractiveness: a review and reevaluation of its role in social skill research. Behavioral Assessment 10, 29-42.

[2] Dion, K., Berscheid, E., \& Walster, E. (1972) What is beautiful is good. Journal of Personality and Social Psychology, 24(3).
[3] Endriga, M. C., \& Kapp-Simon, K. A. (1999). Psychological issues in craniofacial care: state of the art. Cleft Palate-Craniofacial Journal 36 (1), 3-11.

[4] Goffman, E. (1963). Stigma: Note on the management of spoiled identity New York: Simon \& Schuster Inc.

[5] Hodgkinson, R.,\& Lester, H (2002). Stresses and coping strategies of mothers living with a child with cystic fibrosis: implications for nursing professionals. Journal of Advanced Nursing 39 (4), 377-383.

[6] Hagman, G. (2002). The Sense of Beauty. International Journal of Psychoanal 83, 661-674.

[7] Hunt, O., Burden, D., Hepper, P., \& Johnston, C. (2005). The psychosocial effects of CLP: a systematic review. European Journal of Orthodontics 27, 247-285.

[8] Holloway, I., \& Wheerler, S. (2002). Qualitative Research in Nursing (2nd ed). Oxford: Blackwell.

[9] Illich, I. (2003) Medical nemesis. Journal of Epidemiol Community Health. 57 (12) ,919-922.

[10] Jones, E. E., Farina, A., Hastorf, A. H., Markus, H., Miller, D. T., Scott, R. A. (1984). Social stigma: the psychology of marked relationships. W. H. Freeman and Company, New York.

[11] Joachim, G., Acorn, S. (2000). Stigma of visible and invisible chronic conditions. Journal of Advanced Nursing 32 (1), 243-248.

[12] Kelton, R. W. (2001). Facing up to stigma: workplace and personal strategies. Cleft Palate-Craniofacial Journal 38, 245-247.

[13] Lei, R. L., Chen, H. S., Huang, B. Y., Chen, Y. C., Chen, P. K. T., Lee, H. Y., Chang, C. W., \& Wu, C. L. (2013) Population-Based Study of Birth Prevalence and Factors Associated with Cleft Lip and/or Palate in Taiwan 2002-2009. PLOS ONE(3)8.

[14] Lei, R.L., Wang ,S. L., Cheng, C.P., Chen P.K.T., \& Chin, C. C. (2010) Psychometric Evaluation of the Stress Scale for Parents with Cleft Lip and/or Palate Children (SSPCC) - A Preliminary Study. The Cleft Palate-Craniofacial Journal, 47(5), 482-490.

[15] Link, B. G., Struening, E. L., Rahav, M., Phelan, J. C., \& Nuttbrock, L. (1997). On stigma and its consequences: evidence from a longitudinal study of men with dual diagnoses of mental illness and substance abuse. Journal of Health and Social Behavior 38, 177-190.

[16] Noar, M. D. (1991) Endoscopy simulation: a brave new world. Endoscopy . 23, 147-149

[17] Marcusson, A. (2001) Adult patients with treated complete CLP: methodological and clinical studies. Swedish Dental Journal. 145, 1-57

[18] Merleau-Ponty, M. (1962). Phenomenology of Perception(C. Smith, Trans.).London and New York: Poutledge.

[19] Moran, D. (2000). Introduction to phenomenology. London: Routledge.

[20] Persson, M., Aniansson, G., Becker, M., \& Svensson, H. (2002) Selfconcept and introversion in adolescents with CLP. Journal of Plastic Surgery and Hand Surgery.36 (1), 24-27

[21] Pope, A. W., \& Snyder, T. H. (2005). Psychosocial adjustment in children and adolescents with a craniofacial anomaly: age and sex patterns. Cleft Palate-Craniofacial Journal 42 (4), 349-361.

[22] Ramstad, T., Ottem, E., \& Shaw, W. C. (1995). Psychosocial adjustment in Norwegian adults who had undergone standardized treatment of complete CLP. Part I. Education, employment and marriage. Scandinavian Journal of Plastic and Reconstructive Surgery and Hand Surgery 29, 251-257.

[23] Richman, L. C. (1983). Self-reported social, speech, and facial concerns and personality adjustment of adolescents with CLP. Cleft Palate Journal 20 (2), 108-112.

[24] Richman, L. C., Holmes, C. S., \& Eliason, M. J. (1985). Adolescents with CLP: self-perceptions of appearance and behavior related to personality adjustment. Cleft Palate Journal 22 (2), 93-96.

[25] Snyder, H. T., Bilboul, M. J., \& Pope, A. W. (2005). Psychosocial adjustment in adolescents with craniofacial anomalies: a comparison of parent and self-reports. Cleft Palate-Craniofacial Journal 42 (5), 548-555.

[26] Strauss, R.(2001). Childhood Obesity and Self-Esteem. Pediatrics, 105, 111. 